\title{
Mixed halide/oxoanion-templated frameworks
}

\begin{abstract}
Mahbod Morshedi and Nicholas G. White*
A tetrahedral tetra-amidinium compound $1^{4+}$ was crystallised in the presence of a range of anions $\left(\mathrm{Cl}^{-}, \mathrm{Br}^{-}, \mathrm{NO}_{3}{ }^{-}\right.$, oxalate $^{2-}$ ) giving a range of interesting solid state structures assembled through amidinium $\cdots$ anion hydrogen bonding interactions. Mixing the chloride or bromide salts of $\mathbf{1}^{4+}$, i.e. $1.4 \mathrm{Cl}$ or $1.4 \mathrm{Br}$, and inorganic oxalate salts in water gave crystals of ordered three-dimensional network structures containing both oxalate and halide anions. These interesting "mixed anion" frameworks exhibit high thermal stability to heat and hydrolysis but are not significantly porous. Importantly, these materials are significantly more robust than the analogous terephthalatecontaining framework materials.
\end{abstract}

\section{Introduction}

The development of anions as templates for selfassembled supramolecular structures is still in its infancy, presumably due in part to the difficulties of selectively interacting with anions. ${ }^{1}$ Recently however, a range of anion-templated constructs have been reported including the anion-templated syntheses of interlocked structures, ${ }^{2}$ cages $^{3}$ and stimuli-responsive pseudorotaxanes. ${ }^{4}$

While anion-directed self-assembly is underexplored, there has been considerable success in engineering hydrogen-bonded constructs, in particular hydrogenbonded framework materials. Notable results in this area include Ward's guanidinium sulfonate frameworks ${ }^{5}$ and Wuest's neutral hydrogen bonded materials. ${ }^{6}$ More recently, Frišičić has demonstrated that imidazolium cations and sulfate anions form frameworks that are analogous to transition metal imidazolate materials. ${ }^{7}$

Inspired by this work, we recently reported ${ }^{8}$ the aniontemplated synthesis of 3D framework materials taking advantage of the favourable hydrogen bonding interactions between a tetratopic tetra-amidinium receptor $1^{4+}$ and terephthalate (TP) anions (Scheme 1). ${ }^{9}$ Remarkably, these frameworks form in water in minutes and only the terephthalate anion results in the formation of a robust framework, while a range of other anions (halides, nitrate, sulfate, isophthalate) do not give framework materials. The initially-formed tetragonal phase $\left.(\text { tet-[1-2TP }]_{\mathrm{n}}\right)$ contains large, connected pores, and readily converts to an orthorhombic phase containing non-connected pores upon heating. Given that tet-[1-2TP]n loses crystallinity upon drying (and hence does not show gas adsorption), we were interested to see if other salts of $1^{4+}$ could be used to form more stable materials, in particular if the smaller dicarboxylate anion oxalate could be used to prepare a more compact, and potentially more robust framework.

In the present work, we investigate the solid state structures of the chloride, bromide, nitrate and oxalate (ox) salts of $\mathbf{1 4}^{4+}$. While we were unable to synthesise the targeted material $[\mathbf{1 \cdot 2 0 x}]_{n}$, we instead isolated and characterised the novel mixed anion frameworks, $[1 \cdot \mathbf{o x} \cdot 2 \mathrm{Cl}]_{\mathrm{n}}$ and $[1 \cdot \mathbf{o x} \cdot 2 \mathrm{Br}]_{\mathrm{n}}$.

Research School of Chemistry, The Australian National University, ACT, Australia Email: nicholas.white@anu.edu.au; Web:www.nwhitegroup.com

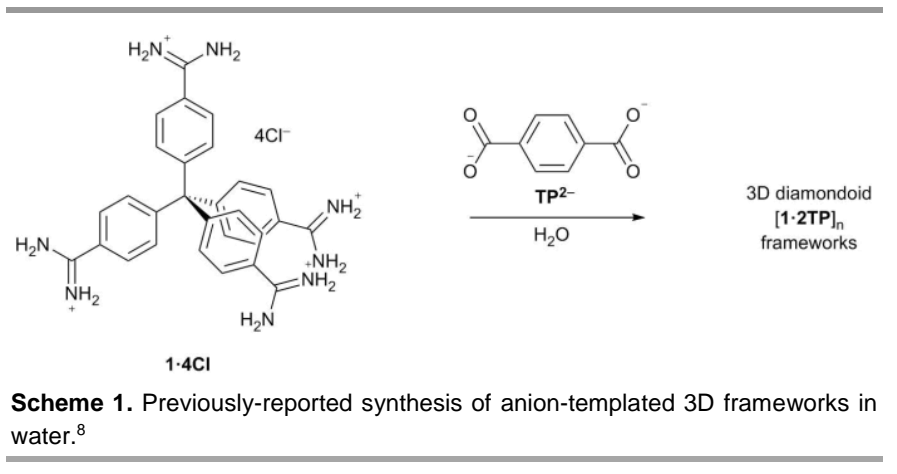

\section{Results and discussion}

\section{Synthesis and structures of $1.4 \mathrm{Cl}, 1.4 \mathrm{Br}$ and $1.4 \mathrm{NO}_{3}$}

The synthesis of $1.4 \mathrm{CI}, 1.4 \mathrm{Br}$ and $1.4 \mathrm{NO}_{3}$ has previously been reported. ${ }^{8}$ Briefly, tetraphenylmethane is selectively tetra-brominated to give tetrakis(4-bromophenyl)methane (2), the bromo- groups are converted to nitrile groups to give tetrakis(4-cyanophenyl)methane (3), and this is then converted to $\mathbf{1}^{4+}$ using LiHMDS (Scheme 2). We have found that the previously-reported method for converting 2 to 3 using copper $(\mathrm{I})$ cyanide in refluxing $\mathrm{DMF}^{10}$ is problematic both in terms of the potential dangers of working with ionic cyanide salts and the difficulties of removing and rendering safe the excess cyanide and other copper salts used during the reaction. Instead, we have found Weissman's procedure ${ }^{11}$ to be advantageous: this uses potassium ferrocyanide(II) as a (relatively) non-toxic cyanide source, and requires only a simple aqueous workup. Using this procedure, we obtained $\mathbf{3}$ in good yield (89\%). Treatment of $\mathbf{3}$ with LiHMDS followed by ethanolic $\mathrm{HCl}$ gives $1 \cdot 4 \mathrm{Cl}$. Anion exchange reactions then give $1.4 \mathrm{Br}$ and $1.4 \mathrm{NO}_{3} .^{8}$

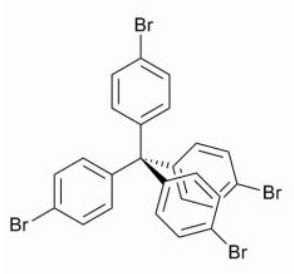

2

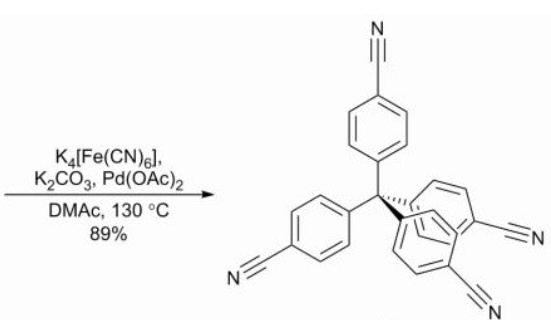

3
Scheme 2. Conversion of $\mathbf{2}$ to $\mathbf{3}$ using Weissman's palladium-catalysed reaction. 
We were able to obtain single crystals of $1.4 \mathrm{CI}, 1 \cdot 4 \mathrm{Br}$ and $1.4 \mathrm{NO}_{3}$ suitable for SCXRD studies by vapour diffusion techniques. The structure of $\mathbf{1 . 4 C l}$ is shown in Figure 1 , and adopts a channel like structure with some of the chloride anions filling these channels. Despite their high positive charge, the tetra-amidinium cations are relatively close-packed, presumably to maximise favourable hydrogen bonding interactions with the chloride anions. These hydrogen bonds are quite short and involve both the "forward" and "sideways" facing amidinium protons $[\mathrm{N} \cdots \mathrm{Cl}$ distances: $3.187(7)-3.375(8) \AA \AA \mathrm{H} \cdots \mathrm{Cl}$ distances: 2.44 $2.55 \AA, 81-85 \%$ of the sum of the van der Waals radii of hydrogen and chlorine $\left.{ }^{12}\right]$.
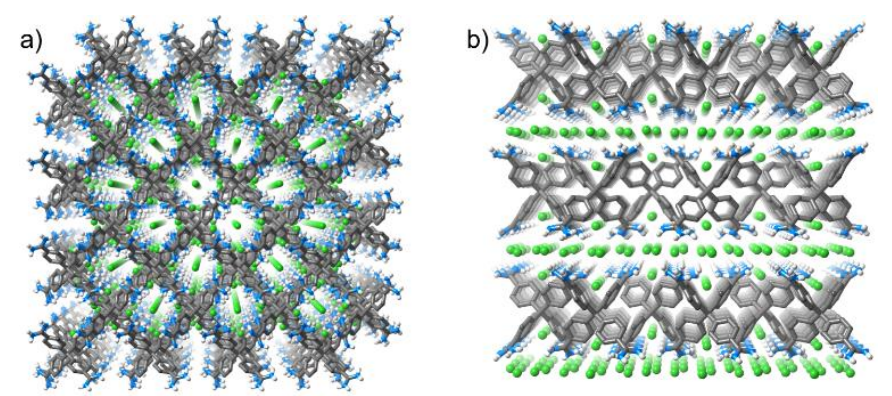

Figure 1. Views of the solid state structure of $\mathbf{1 . 4 C l}$ (some hydrogen atoms omitted for clarity, PLATON-SQUEEZE ${ }^{13}$ used).

The overall structure of $\mathbf{1 . 4 B r}$ is relatively similar to that of $\mathbf{1 . 4 C l}$. Again the tetra-amidinium cations pack relatively closely together forming channels, which are filled with bromide anions (Figure 2). The structure is assembled through $\mathrm{N}-\mathrm{H} \cdots \mathrm{Br}$ hydrogen bonds, with these bonds approximately the same length as those in $\mathbf{1 . 4 C l}$, when accounting for the increased size of bromide compared to chloride $[\mathrm{N} \cdots \mathrm{Br}$ distances: $3.284(2)-3.469(2) \AA$ distances: $2.47-2.70 \AA$, $81-88 \%$ of the sum of the van der Waals radii of hydrogen and bromide ${ }^{12}$ ].
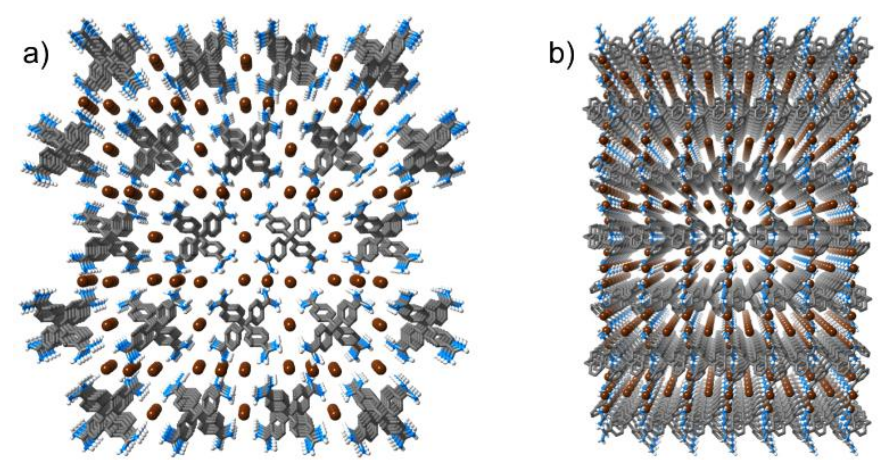

Figure 2. Views of the solid state structure of $\mathbf{1 . 4 B r}$ (some hydrogen atoms omitted for clarity, PLATON-SQUEEZE ${ }^{13}$ used).

Surprisingly, the structure of $\mathbf{1 . 4} \mathrm{NO}_{3}$ (Figure 3 ) is similar to the halide salts of $\mathbf{1 4}^{\mathbf{4}}$, despite containing a polyatomic rather than monoatomic anion. Channels are formed from "pillars" of close-packed tetra-amidinium cations, with nitrate anions and solvent molecules filling these channels.
Amidinium $\cdots$ nitrate hydrogen bonds vary more in length than in the halide anion-containing structures, with some contacts quite short $[\mathrm{N} \cdots \mathrm{O}$ distances: $2.827(12)-3.122(12)$ $\AA$, $\mathrm{H} \cdots \mathrm{O}$ distances: $1.93-2.38 \AA, 71-88 \%$ of the sum of the van der Waals radii of hydrogen and oxygen ${ }^{12}$ ].

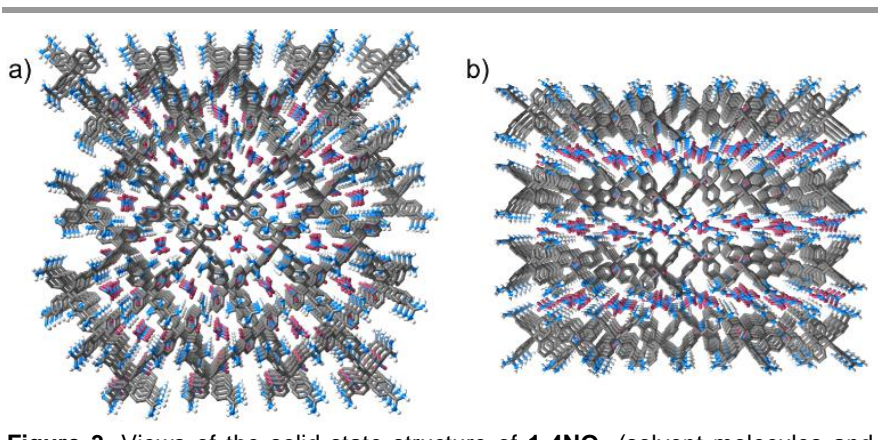

Figure 3. Views of the solid state structure of $1.4 \mathrm{NO}_{3}$ (solvent molecules and some hydrogen atoms omitted for clarity).

While the structures of $1.4 \mathrm{Cl}, 1 \cdot 4 \mathrm{Br}, 1 \cdot 4 \mathrm{NO}_{3}$ appear to be somewhat ordered network structures, it should be noted that these are not "genuine" framework materials. The crystals dissolve readily in polar organic solvents to give sharp ${ }^{1} \mathrm{H}$ NMR spectra, consistent with these solvents disrupting the hydrogen bonding interactions that hold the solid state networks together.

\section{Synthesis and structures of mixed anion frameworks}

We next attempted to prepare frameworks of the form [1.20x]n by mixing aqueous solutions of $1 \cdot 4 \mathrm{Cl}$ and $\mathrm{Na}_{2} \cdot \mathbf{0 x}$, in a manner analogous to that used to prepare [1-2TP]n frameworks. ${ }^{8}$ Mixing aqueous solutions of $1.4 \mathrm{Cl}$ and $\mathrm{Na}_{2} \cdot \mathbf{o x}$ gave a clear, colourless solution, which upon standing for a few hours gave large block-like crystals. However, SCXRD studies revealed that these were not the targeted product $[\mathbf{1 \cdot 2 0 x}]_{n}$ but rather a mixed framework, $[1 \cdot 0 x \cdot 2 \mathrm{Cl}]_{n}$ (Figure 4).

The structure crystallises in the tetragonal space group $\mathrm{P} 4 / \mathrm{n}$, with a quarter of the tetra-amidinium receptor, a quarter of an oxalate anion and two chloride anions (on special positions) within the asymmetric unit cell. The "forward"-facing amidinium hydrogen atoms form hydrogen bonds to an oxalate anion, which is disordered about the four-fold rotation axis [Figures $4 \mathrm{~b}$ and $4 \mathrm{c}, \mathrm{N} \cdots \mathrm{O}=2.778(5)$, $2.789(5) \AA ; \mathrm{H} \cdots \mathrm{O}=1.93,1.93 \AA ; 71 \%$ of the sum of the van der Waals radii of hydrogen and oxygen ${ }^{12}$ ]. The "sideways"-facing amidinium hydrogen atoms form hydrogen bonds to chloride anions [Figure $4 \mathrm{~b}, \mathrm{~N} \cdots \mathrm{Cl}=$ 3.283(4), 3.370(4) $\AA ; \mathrm{H} \cdots \mathrm{Cl}=2.45,2.55 \AA$; 81 and $85 \%$ of the sum of the van der Waals radii of hydrogen and chlorine ${ }^{12}$ ] resulting in a structure that is quite denselypacked. Small $\left(62 \AA^{3}\right.$ ) voids are located about the special positions - these appear to contain water molecules, but it was not possible to sensibly model these solvents and so PLATON-SQUEEZE ${ }^{13}$ was used to include this electron density in the refinement. 

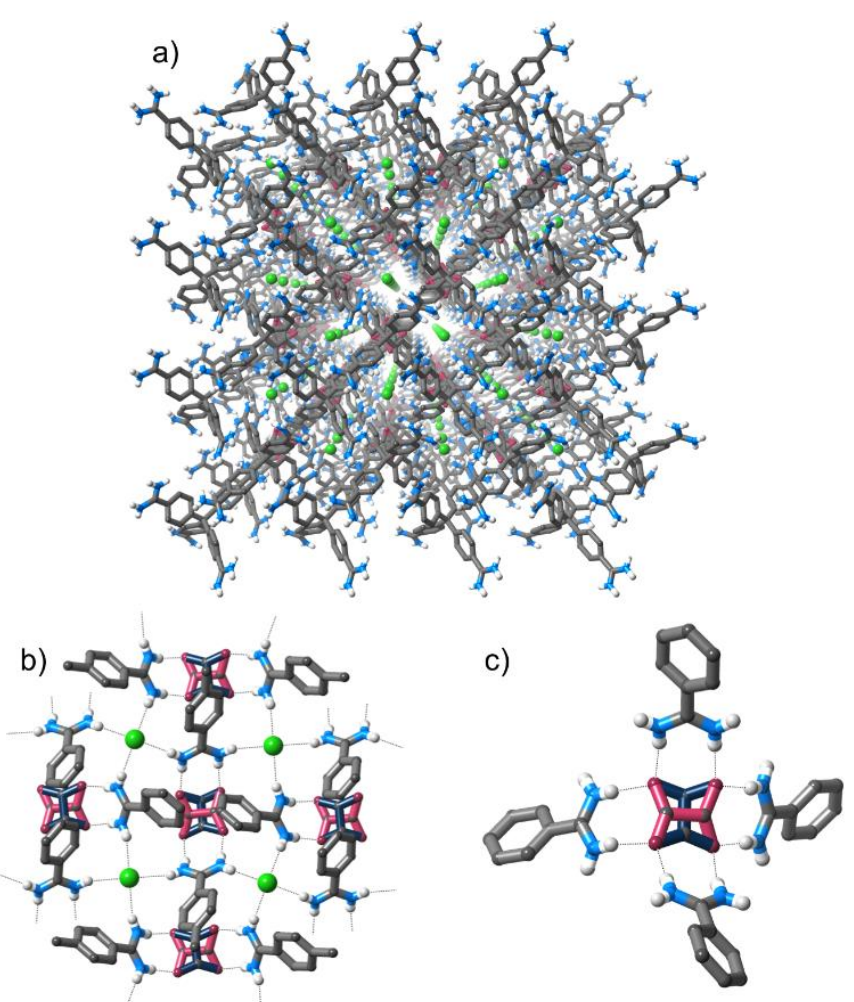

Figure 4. Views of the solid state structure of $[\mathbf{1} \cdot \mathbf{o x} \cdot \mathbf{2} \mathrm{Cl}]_{\mathrm{n}}$ (some hydrogen atom omitted for clarity, two positions of disordered oxalate anion displayed in pink and blue).

We also attempted this synthesis starting from lithium oxalate or tetrabutylammonium oxalate, but in both cases this returned the same product. Using a large excess of sodium oxalate also gave the same mixed anion framework. Mixing 1.4Br and $\mathrm{Na}_{2}$. ox gave the bromidecontaining mixed framework $[\mathbf{1} \cdot \mathbf{o x} \cdot \mathbf{2 B r}]_{\mathrm{n}}$, while no crystals were obtained when starting from $1 \cdot 4 \mathrm{NO}_{3}$. The bromidecontaining mixed anion framework [1-0x-2Br $]_{\mathrm{n}}$ (Figure 5) is isostructural with $[\mathbf{1} \cdot \mathbf{o x} \cdot \mathbf{2} \mathrm{Cl}]_{\mathrm{n}}$ with the same disorder of the oxalate anion and very similar hydrogen bonding arrangements.

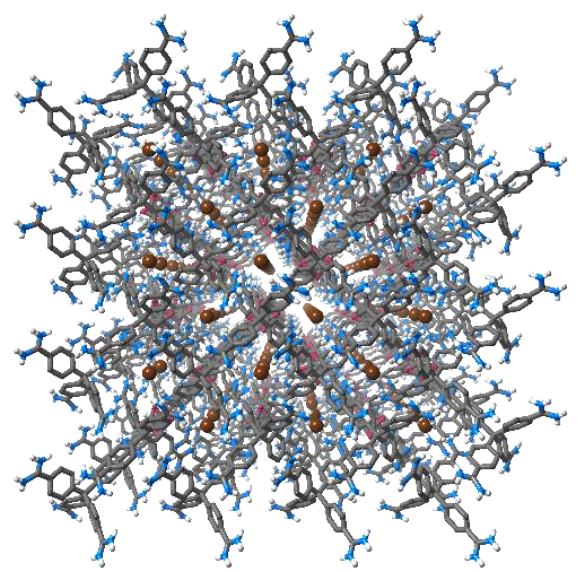

Figure 5 . View of the solid state structure of $[\mathbf{1} \cdot \mathbf{0 x} \cdot \mathbf{2 B r}]_{\mathrm{n}}$ (some hydrogen atoms omitted for clarity).
Both of the mixed anion frameworks form reproducibly and were prepared "in bulk" in good yields by simply mixing aqueous solutions of $1.4 \mathrm{Cl}$ or $1.4 \mathrm{Br}$ and sodium oxalate (93 and $61 \%$ for $[\mathbf{1} \cdot \mathbf{o x} \cdot \mathbf{2} \mathbf{C l}]_{\mathrm{n}}$ and $[\mathbf{1} \cdot \mathbf{o x} \cdot \mathbf{2 B r}]_{\mathrm{n}}$, respectively). ${ }^{14}$ These materials were characterised by ${ }^{1} \mathrm{H}$ NMR spectroscopy of the acid-digested framework (without acid, the frameworks are insoluble in all tested solvents), IR spectroscopy, thermogravimetric analysis (TGA) and powder X-ray diffraction (PXRD) experiments. We also conducted gas adsorption measurements on $[1 \cdot 0 x \cdot 2 \mathrm{Cl}]_{\mathrm{n}}$, which revealed that this material does not absorb $\mathrm{N}_{2}$ gas.

\section{Stability testing of $[1 \cdot 0 \mathrm{x} \cdot 2 \mathrm{Cl}]_{\mathrm{n}}$ and $[1 \cdot \mathrm{ox} \cdot 2 \mathrm{Br}]_{\mathrm{n}}$}

PXRD experiments: PXRD studies revealed that both $[1 \cdot 0 x \cdot 2 \mathrm{Cl}] \mathrm{n}$ and $[1 \cdot \mathbf{0 x} \cdot \mathbf{2 B r}]_{\mathrm{n}}$ retain good crystallinity on drying, and that the structure of the bulk material is consistent with that observed by SCXRD experiments. We

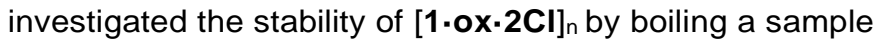
of this material in water for two hours. No change in the PXRD pattern of the material was observed upon boiling (Figure 6), suggesting that the frameworks are stable with respect to hydrolysis. This is in contrast to $[1-2 T P]_{n}$, which converts from a tetragonal to orthorhombic phase upon boiling in water. ${ }^{8}$

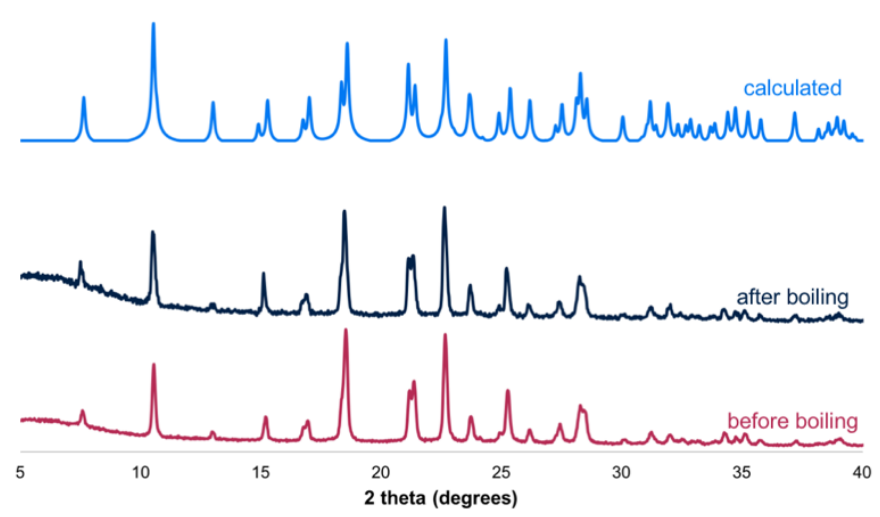

Figure 6. PXRD pattern of $[\mathbf{1} \cdot \mathbf{o x} \cdot \mathbf{2} \mathrm{Cl}]_{\mathrm{n}}$ before and after boiling in water for two hours. The pattern calculated from the SCXRD structure is provided for comparison.

TGA experiments: TGA traces were recorded for both of the mixed halide/oxalate frameworks. These suggest the presence of a small amount of included solvent (consistent with conclusions drawn from SCXRD experiments), which is removed upon initial heating. The materials then remain stable until approximately $280{ }^{\circ} \mathrm{C}$ - surprisingly high considering these supramolecular materials are held together by relatively weak hydrogen bonding interactions. Figure 7 shows the TGA traces from 30 to $350{ }^{\circ} \mathrm{C}$ for $[1 \cdot 0 x \cdot 2 \mathrm{Cl}]_{\mathrm{n}}$ and $[1 \cdot \mathbf{0 x} \cdot \mathbf{2 B r}]_{\mathrm{n}}$, as well as both phases of the terephthalate-based framework $[1.2 T P]_{n}$ (full decomposition traces for $[\mathbf{1} \cdot \mathbf{o x} \cdot \mathbf{2} \mathrm{Cl}]_{\mathrm{n}}$ and $[\mathbf{1} \cdot \mathbf{o x} \cdot \mathbf{2 B r}]_{\mathrm{n}}$ are provided in the ESI). It is noticeable that the mixed halide/oxalate frameworks show significantly higher thermal stability than the analogous terephthalatecontaining materials, ${ }^{8}$ in which thermal decomposition begins at approximately $230^{\circ} \mathrm{C}$. 


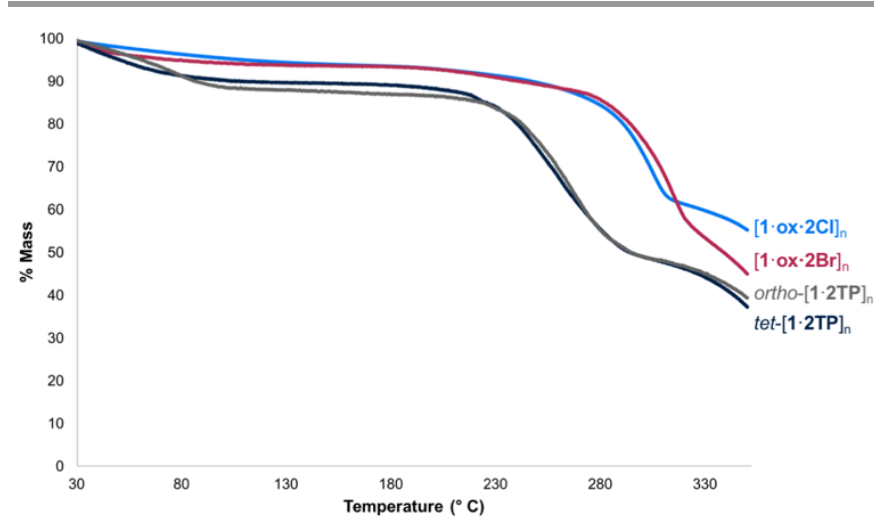

Figure 7. TGA traces of $[\mathbf{1} \cdot \mathbf{o x} \cdot \mathbf{2} \mathrm{Cl}]_{\mathrm{n}}$ and $[\mathbf{1} \cdot \mathbf{o x} \cdot \mathbf{2 B r}]_{\mathrm{n}}$ and comparison with TGA traces of tetragonal and orthorhombic phases of $[1 \cdot 2 \mathrm{TP}]_{\mathrm{n}}{ }^{8}$

\section{Conclusions}

Several salts of the tetra-amidinium receptor $\mathbf{1}^{4+}$ were structurally characterised; in all cases the structures are assembled through relatively short $\mathrm{N}-\mathrm{H} \cdots$ anion hydrogen bonds. The halide salts $1.4 \mathrm{Cl}$ and $1.4 \mathrm{Br}$ react with sodium oxalate in water to give crystalline framework materials. Surprisingly, these are not the targeted $[\mathbf{1 \cdot 2 0 x}]_{\mathrm{n}}$ networks, but rather the new mixed-anion containing frameworks $[1 \cdot 0 x \cdot 2 \mathrm{Cl}]_{\mathrm{n}}$ and $[\mathbf{1} \cdot \mathbf{0 x} \cdot \mathbf{2 B r}]_{\mathrm{n}}$. These materials are relatively tightly-packed, and show noticeably higher thermal stability than the related framework [1-2TP]n. We are continuing to investigate these types of hydrogen bonded anioncontaining materials, with the aim of combining an open, porous structure and the high stability observed herein.

\section{Experimental}

\section{Synthesis and characterisation}

General remarks: Solvents and reagents were bought from commercial suppliers and used as received. Tetrakis(4bromophenyl)methane was prepared by bromination of tetraphenylmethane as previously described. ${ }^{10}$ While tetraphenylmethane is commercially-available, for cost reasons it was prepared in two steps from triphenylmethyl chloride as previously described. ${ }^{15} \mathbf{1 . 4 C I}, 1.4 \mathrm{Br}$ and $1.4 \mathrm{NO}_{3}$ were prepared from $\mathbf{3}$ as previously described. ${ }^{8}$ Details of instrumentation are given in the ESI.

Tetrakis(4-cyanophenyl)methane (3): To a Schlenk flask was added de-oxygenated DMAc $(25 \mathrm{~mL})$, followed by tetrakis(4bromophenyl)methane $2(1.0 \mathrm{~g}, 1.6 \mathrm{mmol})$, potassium ferrocyanide(II) trihydrate $(1.4 \mathrm{~g}, 3.2 \mathrm{mmol})$ and sodium carbonate $(0.68 \mathrm{~g}, 6.4 \mathrm{mmol})$. The mixture was again deoxygenated with bubbling nitrogen, and palladium(II) acetate (29 mg, $8 \mathrm{~mol} \%$, $2 \mathrm{~mol} \%$ per bromo group) was added. The reaction was then heated to $130{ }^{\circ} \mathrm{C}$ overnight under a nitrogen atmosphere. The resulting dark brown suspension was cooled to room temperature, and then diluted with dichloromethane (50 $\mathrm{mL}$ ). The solution was filtered, and the filtrate taken to dryness under reduced pressure. The resulting brown oil was dissolved in dichloromethane $(2 \mathrm{~mL})$ and pet. spirits added until no more precipitation was observed ( $70 \mathrm{~mL}$ ). The cream-coloured powder was isolated by filtration, washed with pet. spirits and air dried to give 3. Yield: $0.59 \mathrm{~g}(1.4 \mathrm{mmol}, 89 \%)$.

Spectral data were consistent with those previously-reported. ${ }^{16}$ ${ }^{1} \mathrm{H}$ NMR $\left(\mathrm{CDCl}_{3}\right): 7.64(\mathrm{~d}, J=8.5 \mathrm{~Hz}), 7.27(\mathrm{~d}, J=8.5 \mathrm{~Hz}) \mathrm{ppm}$. ${ }^{13} \mathrm{C} \mathrm{NMR}\left(\mathrm{CDCl}_{3}\right)$ : 148.7, 132.5, 131.2, 118.0, 111.8, $65.8 \mathrm{ppm}$.

[1. ox $\cdot 2 \mathrm{Cl}]_{\mathrm{n}}$ : A solution of sodium oxalate $(5.5 \mathrm{mg}, 0.040 \mathrm{mmol})$ in water $(3 \mathrm{~mL})$ was added to a solution of $1.4 \mathrm{Cl}(13 \mathrm{mg}, 0.020$ $\mathrm{mmol}$ ) in water $(2 \mathrm{~mL})$. The clear colourless solution was left to stand for three days, after which the resulting very pale yellow crystals were isolated by filtration, washed with water and air dried. Yield: $13 \mathrm{mg}(0.19 \mathrm{mmol}, 93 \%)^{14 \dagger}$.

${ }^{1} \mathrm{H}$ NMR $\left[\mathrm{d}_{6}-\mathrm{DMSO}\right.$ containing a drop conc. DCl $\left.(\mathrm{aq})\right]$ : $9.60^{*}(\mathrm{br}$. s), 9.34* (br. s), 7.95 (d, $J=8.4 \mathrm{~Hz}, 8 \mathrm{H}), 7.55(\mathrm{~d}, J=8.4 \mathrm{~Hz}$, $8 \mathrm{H}$ ) ppm. IR (inter alia): 1694, 1609, 1567, 1532, 1482 (strong) $\mathrm{cm}^{-1}(\mathrm{C}=\mathrm{O}, \mathrm{C}=\mathrm{N}$ and $\mathrm{C}=\mathrm{C}$ stretches $)$.

*These peaks integrate to a value lower than the expected $8 \mathrm{H}$, presumably due to $H / D$ exchange.

${ }^{\dagger} \mathrm{Mmol}$ and \& yield corrected to account for $\sim 6.5 \%$ water, as indicated by TGA.

$[\mathbf{1} \cdot \mathbf{o x} \cdot \mathbf{2} \mathrm{Cl}]_{\mathrm{n}}$ was also characterised by SCXRD, PXRD and TGA (see ESI).

[1-ox-2Br] : A solution of sodium oxalate $(6.7 \mathrm{mg}, 0.050 \mathrm{mmol})$ in water $(2 \mathrm{~mL})$ was added to a solution of $1.4 \mathrm{Br}(20 \mathrm{mg}, 0.025$ $\mathrm{mmol}$ ) in water $(2 \mathrm{~mL})$. The clear colourless solution was left to stand for three days, after which the resulting very pale yellow crystals were isolated by filtration, washed with water and air dried. Yield: $12 \mathrm{mg}(0.015 \mathrm{mmol}, 61 \%)^{14 \dagger}$.

${ }^{1} \mathrm{H}$ NMR [ $\mathrm{d}_{6}-\mathrm{DMSO}$ containing a drop conc. $\mathrm{DCl}_{(\mathrm{aq})}$ ]: $9.53^{*}(\mathrm{br}$. s), $9.27^{*}$ (br. s), 7.93 (d, $\left.J=8.3 \mathrm{~Hz}, 8 \mathrm{H}\right), 7.56$ (d, $J=8.3 \mathrm{~Hz}$, $8 \mathrm{H}$ ) ppm. IR (inter alia): 1694, 1608, 1567, 1531, 1483 (strong) $\mathrm{cm}^{-1}(\mathrm{C}=\mathrm{O}, \mathrm{C}=\mathrm{N}$ and $\mathrm{C}=\mathrm{C}$ stretches $)$.

*These peaks integrate to a value lower than the expected $8 \mathrm{H}$, presumably due to $H / D$ exchange.

${ }^{\dagger} \mathrm{Mmol}$ and $\%$ yield corrected to account for $\sim 6.5 \%$ water, as indicated by TGA.

[1-ox-2Br $]_{n}$ was also characterised by SCXRD, PXRD and TGA (see ESI).

\section{X-ray crystallography}

Single crystal data were collected using mirrormonochromated $\mathrm{Cu} \mathrm{Ka}$ radiation at $150 \mathrm{~K}$ on an Agilent Supernova diffractometer. Raw frame data (including data reduction, interframe scaling, unit cell refinement and absorption corrections) were processed using CrysAlis PRO. ${ }^{17}$ Structures were solved with SUPERFLIP ${ }^{18}$ and refined using full-matrix least-squares on $F^{2}$ within the CRYSTALS suite. ${ }^{19}$ All non-hydrogen atoms were refined with anisotropic displacement parameters. $\mathrm{C}-\mathrm{H}$ hydrogen atoms were generally visible in the Fourier difference map, and were initially refined with restraints on bond lengths and angles, after which the positions were used as the basis for a riding model. ${ }^{20} \mathrm{O}-\mathrm{H}$ and $\mathrm{N}-\mathrm{H}$ hydrogen atoms were generally visibly in the Fourier difference map, and 
their positions were refined with restraints on bond lengths and angles. Selected crystallographic data are summarized in Table S1, and full crystallographic data are provided in CIF format as Supporting Information (CCDC Numbers: 1531015-1531019).

\section{Acknowledgements}

The authors thank Prof. Christian Doonan (University of Adelaide) for conducting porosity measurements. NGW thanks the Australian Research Council for a Discovery Early Career Researcher Award fellowship (DE170100200).

\section{Notes and references}

1. a) N. H. Evans and P. D. Beer, Angew. Chem., Int Ed., 2014, 53, 11716-11754; b) P. A. Gale, E. N. W. Howe and X. Wu, Chem, 2016, 1, 351-422.

2. a) M. D. Lankshear and P. D. Beer, Acc. Chem. Res., 2007, 40, 657-668; b) G. T. Spence and P. D. Beer, Acc. Chem. Res., 2013, 46, 571-586; c) M. J. Langton, S. W. Robinson, I. Marques, V. Felix and P. D. Beer, Nat. Chem., 2014, 6, 10391043; d) S. W. Robinson, C. L. Mustoe, N. G. White, A. Brown, A. L. Thompson, P. Kennepohl and P. D. Beer, J. Am. Chem. Soc., 2015, 137, 499-507; e) M. K. Chae, J.-m. Suk and K.-S. Jeong, Tetrahedron Lett., 2010, 51, 4240-4242.

3. a) B. Wu, F. Cui, Y. Lei, S. Li, N. d. S. Amadeu, C. Janiak, Y.-J. Lin, L.-H. Weng, Y.-Y. Wang and X.J. Yang, Angew. Chem., Int. Ed., 2013, 52, 50965100; b) D. Yang, J. Zhao, Y. Zhao, Y. Lei, L. Cao, X.-J. Yang, M. Davi, N. Amadeu de Sousa, C. Janiak, Z. Zhang, Y.-Y. Wang and B. Wu, Angew. Chem., Int. Ed., 2015, 54, 8658-8661; c) K. Pandurangan, J. A. Kitchen, S. Blasco, E. M. Boyle, B. Fitzpatrick, M. Feeney, P. E. Kruger and T. Gunnlaugsson, Angew. Chem., Int. Ed., 2015, 54, 4566-4570.

4. a) H.-Y. Gong, B. M. Rambo, E. Karnas, V. M. Lynch and J. L. Sessler, Nat. Chem., 2010, 2, 406409; b) H.-Y. Gong, B. M. Rambo, E. Karnas, V. M. Lynch, K. M. Keller and J. L. Sessler, J. Am. Chem. Soc., 2011, 133, 1526-1533; c) H.-Y. Gong, B. M. Rambo, V. M. Lynch, K. M. Keller and J. L. Sessler, Chem. Eur. J., 2012, 18, 7803-7809; d) H.-Y. Gong, B. M. Rambo, V. M. Lynch, K. M. Keller and J. L. Sessler, J. Am. Chem. Soc., 2013, 135, 6330-6337.

5. a) M. J. Horner, K. T. Holman and M. D. Ward, J. Am. Chem. Soc., 2007, 129, 14640-14660; b) W Xiao, C. Hu and M. D. Ward, J. Am. Chem. Soc., 2014, 136, 14200-14206; c) Y. Liu, W. Xiao, J. J. $\mathrm{Yi}, \mathrm{C} . \mathrm{Hu}, \mathrm{S}$.-J. Park and M. D. Ward, J. Am. Chem. Soc., 2015, 137, 3386-3392; d) T. Adachi and M. D. Ward, Acc. Chem. Res., 2016, 49, 2669-2679.

6. a) M. Simard, D. Su and J. D. Wuest, J. Am Chem. Soc., 1991, 113, 4696-4698; b) X. Wang, M. Simard and J. D. Wuest, J. Am. Chem. Soc., 1994, 116, 12119-12120; c) P. Brunet, M. Simard and J. D. Wuest, J. Am. Chem. Soc., 1997, 119, 2737-2738; d) J. D. Wuest, Chem. Commun., 2005, 5830-5837; e) K. E. Maly, E. Gagnon, T.
Maris and J. D. Wuest, J. Am. Chem. Soc., 2007, 129, 4306-4322.

7. C. Mottillo and T. Friscic, Chem. Commun., 2015 51, 8924-8927.

8. M. Morshedi, M. Thomas, A. Tarzia, C. J. Doonan and N. G. White, Chem. Sci., 2017, DOI: $10.1039 / \mathrm{c} 7 \mathrm{sc} 00201 \mathrm{~g}$.

9. The amidinium $\cdots$ carboxylate interaction has been used to prepare other self-assembled systems including 1D polymers, helices and cages. Selected examples: a) M. W. Hosseini, R. Ruppert, P. Schaeffer, A. De Cian, N. Kyritsakas, J. Fischer, J. Chem. Soc. Chem. Commun., 1994, 2135-2136; b) F. Corbellini, L. Di Costanzo, M. Crego-Calama, S. Geremia, D. N. Reinhoudt, J. Am. Chem. Soc., 2003, 125, 9946-9947; c) Y. Tanaka, H. Katagiri, Y.Furusho, E. Yashima, Angew. Chem., Int. Ed., 2005, 44, 3867-3870; d) M. Ikeda, Y. Tanaka, T. Hasegawa, Y. Furusho, E. Yashima, J. Am. Chem. Soc., 2006, 128, 68066807; e) H. Katagiri, Y. Tanaka, Y. Furusho, E. Yashima, Angew. Chem., Int. Ed. 2007, 46, 24352439; f) Y. Nakatani, Y. Furusho, E. Yashima, Angew. Chem., Int. Ed. 2010, 49, 5463-5467.

10. B. F. Hoskins and R. Robson, J. Am. Chem. Soc., 1989, 111, 5962-5964.

11. S. A. Weissman, D. Zewge and C. Chen, J. Org. Chem., 2005, 70, 1508-1510.

12. S. Alvarez, Dalton Trans., 2013, 42, 8617-8636.

13. a) P. van der Sluis and A. L. Spek, Acta Crystallogr., 1990, A46, 194-201; b) A. Spek, J. Appl. Crystallogr., 2003, 36, 7-13.

14. Given the small scales that these materials were prepared on, the percentage yields are relatively imprecise.

15. T. J. Zimmermann and T. J. J. Müller, Synthesis, 2002, 2002, 1157-1162.

16. B. F. Hoskins and R. Robson, J. Am. Chem. Soc., 1990, 112, 1546-1554.

17. CrysAlis PRO, 2011, Agilent Technologies.

18. L. Palatinus and G. Chapuis, J. Appl. Crystallogr., 2007, 40, 786-790.

19. P. W. Betteridge, J. R. Carruthers, R. I. Cooper, K. Prout and D. J. Watkin, J. Appl. Crystallogr., 2003, 36, 1487.

20. R. I. Cooper, A. L. Thompson and D. J. Watkin, J. Appl. Crystallogr., 2010, 43, 1100-1107. 